\title{
LOS DESASTRES DE LA GUERRA: \\ SOBRE LA ARTICULACIÓN DE LA IRONÍA EN LOS CUENTOS "LA RECIÉN NACIDA SANGRE", DE LUIS RAFAEL SÁNCHEZ Y "EL MOMENTO DIVINO DE CARUSO LLOMPART", DE FÉLIX CÓRDOVA ITURREGUI
}

\section{POR}

\author{
CARMEN VÁZQUEZ ARCE \\ Universidad de Puerto Rico
}

\section{INTRODUCCIÓN}

Las relaciones de dominación imperialista impuestas por los Estados Unidos en Puerto Rico, a raíz de la guerra expansionista de 1898, han obligado a los puertorriqueños a participar en las guerras declaradas y no declaradas de la metrópoli. En 1917, cuando el Congreso norteamericano concedió la ciudadanía estadounidense a los puertorriqueños mediante la Ley Jones, se legalizó la conscripción militar e inmediatamente se impuso el servicio militar obligatorio (Véase Rodríguez Beruff, 1988). Esta medida, provocada en parte por la situación de guerra, contribuyó a que se estrecharan los intereses estratégicos y políticos de los Estados Unidos en Puerto Rico (véase M.E. Estades, 1988). El servicio militar obligatorio ha funcionado además como un medio de control social: ha sido una válvula de escape al desempleo, ha mantenido ocupado a un sector de la población en edad productiva y luego lo ha sostenido con pensiones, evitando de esta manera desatar la fuerza social de los desempleados. Por otro lado, junto a la emigración y a la esterilización en masa de las mujeres puertorriqueñas, ha servido a la ideología racista de la sobrepoblación (véase $\mathrm{N}$. García, 1978) como un medio de control poblacional. Finalmente, el reclutamiento de puertorriqueños para servir en las fuerzas armadas de los Estados Unidos ha producido un impacto ideológico que habría que estudiar, sobre todo en aquellos sectores de la burguesía puertorriqueña que pertenecen a la Guardia Nacional o que se forman en el Reserve Officers Training Corps.

Los escritores puertorriqueños han examinado esta situación de opresión desde diversas perspectivas. La generación de Pedro Juan Soto, Emilio Díaz Valcárcel, René Marqués, Edwin Figueroa, Abelardo Díaz Alfaro y José Luis González, llamada unas veces generación de la Segunda Guerra y otras generación del ' 50 , trató en sus cuentos el tema de la Segunda Guerra Mundial y de la Guerra de Corea, que tantas bajas y mutilados produjo entre los soldados puertorriqueños. También trabajó el problema de las tropas norteamericanas estacionadas en la isla o de los Marines en su paso por San Juan y sus consecuencias sociales: antagonismo entre los puertorriqueños y los soldados, 
la proliferación de bares y prostíbulos, etc. Tales experiencias se formulan ficticiamente desde la perspectiva del realismo. Un realismo influido, en algunos casos, por los narradores norteamericanos y europeos como Faulkner, Hemingway, James Joyce, Virginia Woolf y que muchas veces se tiñe de ironía y de elementos absurdos. Un denominador común de estos narradores es que narran la experiencia de la guerra. Ésta se introduce en el presente de los personajes, ya sean éstos los protagonistas o los miembros de la sociedad, y sirve como el trasfondo que produce sentido de culpa, enajenación, locura, llanto desgarrador por la muerte del soldado, racismo. Tal es el caso de "Esta noche no" y "Una caja de plomo que no se podía abrir" de José Luis González; de "El sapo en el espejo" y "El soldado Damián Sánchez", de Emilio Díaz Valcárcel.

Luis Rafael Sánchez, a su vez, articula el tema de la guerra de Corea en el cuento "La recién nacida sangre" como epígono paródico al manejo del tema por la narrativa anterior. Sánchez pertenece a la siguiente generación, que hemos situado en 1966, año en que comienza lo que Neftalí García (1978) ha llamado la tercera fase de inversión de capital norteamericano en Puerto Rico. Este período se caracteriza por cambios sustanciales en la estructura económica y está dominado por la inversión de capital en la industria petroquímica, química, farmacéutica y electrónica. En 1968 se rompe la hegemonía del Partido Popular Democrático y, a causa de una división interna, el Partido Nuevo Progesista, de tendencia anexionista, ganó las elecciones. En este momento de cambios económicos y políticos se producen nuevas formas culturales que en la música y la literatura buscan estructuras más libres: transformación de los géneros, sincretismo, humor, ingreso de lo soez y de la sexualidad en el discurso, presencia de los marginados sociales de la ciudad: adictos a drogas, desempleados, mujeres, negros, homosexuales.

En 1966 Luis Rafael Sánchez publica su libro de cuentos, En cuerpo de camisa. El texto expresa los rasgos arriba mencionados, pero su aportación fundamental es el cambio que se produce en el manejo del material narrativo. Sánchez elimina la diferencia entre el discurso del narrador y el discurso de los personajes. Esta fusión tiene su fundamento en la afirmación del habla puertorriqueña como lengua de cultura. Sánchez "escribe en puertorriqueño", como afirmará más tarde en sus ensayos, porque asume una posición crítica frente al discurso narrativo oficial y rechaza laidea colonizada de la superioridad de la lengua (paradigma) sobre el "dialecto" (habla puertorriqueña). Este cambio permite el ingreso al discurso del humor puertorriqueño, su plebeyización (véase José Luis González, 1980), y también el uso de lo soez. La mirada crítica frente a la generación anterior y frente a la tradición literaria permea la literatura de Sánchez de un fuerte elemento paródico. Ejemplos de esta característica lo son: la parodia del "Tun tun de pasa y grifería" de Luis Palés Matos en Aleluya negra; de la literatura medieval española, en el "Ejemplo del muerto que se murió sin avisar que se moría", y el cuento que comentaremos en este trabajo, "La recién nacida sangre". 
La situación histórica y social de cambio se expresa, pues, en una literatura opuesta, como diría Bakhtin, a la cultura oficial, al tono serio que el mundo de la risa construye como una anti-cultura ${ }^{1}$ (sobre este concepto véase a Lotman 1979; Bakhtin 1974; Halliday, 1978; Hodge \& Kress 1988). Así, cuando el narrador asume el lenguaje de la anticultura produce una serie de significados que operan como un antilenguaje:

these are languages generated not by agents of the state but the opposite: criminals, prisoners, groups that have been marginalized by the state, who express their opposition by creating a language which excludes outsiders (Halliday 1978 citado de Hodge \& Kress 1988, 68).

La negación o inversión de los discursos oficiales produce la ironía y, al mismo tiempo, exige un lector cómplice que pueda penetrar en dicho lenguaje.

Se trata, entonces, de expresar un mundo conflictivolleno de contradicciones, de luchas sociales y políticas, de dependencia económica, un mundo de explotación y opresión cuyo significado mayor es la violencia. Violencia que surge precisamente de la relación colonial y deforma todos los contenidos. El propio Sánchez justifica el uso del humor como resultado de dicha realidad violenta:

Mi mirada como escritor es siempre estridente y distorsionante, porque la realidad se me propone en sus elementos distorsionantes, grotescos, retorcidos. Hay situaciones dentro de nuestro medio que no admiten ... un tratamiento trágico, sino que hay que asediarlas irreverentemente (Sin Nombre, abriljunio 1981) 27.

El acercamiento humorístico no parte exclusivamente de la realidad, sino de la propuesta teórica de Pirandello(1920) y de la corriente del grotesco realista a la que pertenecen según Bakhtin (1974), Thomas Mann, Bertold Brecht, Pablo Neruda y que "continúa la tradición del realismo grotesco y de la cultura popular, reflejando a veces la influencia directa de las formas carnavalescas" (47) en la que habria que ubicar a Sánchez. Por otro lado, la literatura de Valle Inclán y su práctica de lo esperpéntico, autor estudiado por Sánchez en su dimensión de crítico literario, influyen en la visión grotesca de la realidad colonial. Ahora bien, Sánchez reconoce una deuda fundamental con un escritor puertorriqueño de la generación del '30: Emilio S. Belaval. En los Cuentos para fomentar el turismo, encuentra el lenguaje de la violencia y un modelo de escritura:

Emilio S. Belaval descubre, pues, un lenguaje nuevo con que asir la realidad puertorriqueña. Esa es la primera aportacion suya a la literatura. El lenguaje

\footnotetext{
1 "Nuestro mundo oficial tiene la densidad de la zarzuela y la opereta. Un pavoroso mundo de apariencia y cartón". Luis Rafael Sánchez y A. Diaz Quiñones (1979), "El oficio y la memoria" (inédito), lia sesión, 8.
} 
que descubre e invenciona Emilio S. Belaval es el lenguaje de la ironía, de la mordacidad, de la esperpentización, de la parodia, de la burla, de la acusación; lenguajes, en fin, que arrancan de una única esencia: la violencia. ... con la palabra, Belaval nos cuenta el infinito anecdotario de la violencia. Y la palabra misma participa de la violencia, se contamina de ramificaciones violentas; la sintaxis se encrespa, la palabra como unidad se precipita en torrentes nominadores, las imágenes se retuercen (Luis R. Sánchez, 1979), 254-255.

Esta cita describe simultáneamente la práctica narrativa de Belaval y la del propio Sánchez.

La reconocida admiración por el texto de Belaval plantea el problema de la ruptura, que ya hemos apuntado anteriormente (C. Vázquez Arce, 1984, inédito). Se trata de una ruptura con la generación anterior, pero ruptura que incluye la recuperación de discursos anteriores; en este caso, la propuesta estilística de Los cuentos para fomentar el turismo (1946).

El lenguaje retorcido y grotesco de la ironía le servirá a Sánchez para expresar el contexto violentoen el que viven sus personajes. Desde la publicación de En cuerpo de camisa, pasando por La guaracha del Macho Camacho hasta la publicación de Quíntuples, el discurso literario se vuelve cada vez más exagerado y distorsionante, como si esa intensificación respondiera al proceso de crisis que se desarrolla en la sociedad colonial puertorriqueña.

Justo en medio de este proceso aparece otro texto emparentado de alguna manera con la literatura de Sánchez y los Cuentos para fomentar el turismo de Belaval. Se trata de la publicación en 1987 del libro de cuentos El rabode lagartija de aquel famoso señor rector y otros cuentos de orilla de Félix Córdova Iturregui. Curiosamente, pese a la distancia temporal que separa los textos de Sánchez y el de Córdova, podemos detectar algunas afinidades y marcar algunas diferencias. Para ello, analizaremos el mencionado cuento de Sánchez y "El momento divino de Caruso Llompart", de Córdova.

El libro de cuentos de Córdova aparece en un momento de aguda crisis social, cuando la dependencia de los fondos del gobierno de Estados Unidos se incrementa para mantener funcionando la Colonia. Entre el período anterior y este momento se produjo la intervención de los Estados Unidos en la Guerra de Vietnam y el consecuente reclutamiento de puertorriqueños para destacarlos en el frente de guerra. Los resultados de la guerra se manifiestan en los cuentos "Las gallinas blancas de doña Carmela", "Aquel amanecer del negro Chita", "Los corajes de mi hermano Agapito" y "El momento divino de Caruso Llompart". Vietnam es un hecho pasado que afecta el presente de los protagonistas, veteranos de la guerra. O en el caso de "Aquel amanecer del negro Chita", la presencia del ejército norteamericano de ocupación y su policía militar obligan al personaje a morir combatiendo frente al poder militar. Este cuento, en específico, constituye una parodia de los textos de la generación del '50: "En el fondo del caño hay un negrito" de José Luis González y "En una ciudad llamada San Juan”, de René Marqués. 
El "Negrito barrigón, que apareció una mañana entre las casuchas del mangle", no murió en el fondo del caño sino que se convirtió en un negroinmenso y musculoso cuyas grandes manos mataron a dos "empis" que se pusieron en su camino de solidaridad de clase. El negro Chita no es, definitivamente, el puertorriqueño dócil ni la representación de la ciudad a la que debe "salvar", salvándose, sin "noción alguna de cómo hacerlo" (R. Marqués, 1970, 206). El Negro Chita se enfrenta a los militares con plena conciencia, con indignación "Sintió una cócora milenaria encaramársele cuando vio la mirada azul del insolente extranjero" (Córdova, 1987, 32) y "les cortó el paso en la puerta con sus manos desarrolladas" (31-32).

Como vemos, la parodia implica una mirada crítica a la literatura anterior. La ironía, en su doble discurso, establece el diálogo retador entre lo que se dice y lo que se quiere decir realmente. De esta manera, tanto Sánchez como Córdova utilizan procedimientos discursivos similares para enfrentarse a la tradición anterior. Por otro lado, habría que situar también a Córdova dentro de la corriente del realismo grotesco con influencia marcada de Bertold Brecht, y de su teoría del distanciamiento crítico, en especial su concepción de realismo:

nuestro concepto de realismo es amplio y político ... realista es lo que denuncia el complejo causal en la sociedad, es lo que desenmascara los puntos de vista dominantes y los señala como puntos de vista dominantes (B. Brecht, 1976), 64 .

Curiosamente Córdova, al igual que Sánchez, reconoce un parentesco estilístico con el texto de Belaval, Cuentos para fomentar el turismo. Incluso, ambos escritores se han interesado en analizar críticamente el mencionado texto. Sánchez hizo su tesis doctoral sobre Belaval, Fabulación e ideología en la cuentística de Emilio S. Belaval (1979), y Córdova nos ofrece en este volumen de la Revista Iberoamericana su trabajo "La ironía en Cuentos para fomentar el turismo, de Emilio S. Belaval”. El análisis le permite adentrarse en sus estrategias y recursos, entender el humor y el realismo de las narraciones. El crítico Sebastián Cabrer $(1987,25)$ señala que el texto de Córdova se destaca más por "un lenguaje apretado que por el uso del diminutivo y por la fina ironía que lo inunda recuerda a veces a Emilio S. Belaval".

Al igual que los textos de Sánchez, las narraciones de Córdova expresan un lenguaje nuevo y distinto del de sus coetáneos del momento, pese a que coincide con ellos en el uso del humor. Como Sánchez, regresa a los Cuentos para fomentar el turismo para encontrar unas estrategias discursivas que le permitan develar toda la complejidad y violencia de las estructuras de poder y sus discursos, así como los discursos dominantes. Inserto en una tradición literaria, como ha señalado Eliseo Colón (198), polemiza con ella y en su discurso irónico descubre también los discursos dominantes de la institución literaria puertorriqueña. De esta manera se instaura en el discurso oculto tras los enunciados literales el rechazo de la ideología del pesimismo, del puertorriqueño dócil, del idealismo 
que habla de "el puertorriqueño" como representación y esencia de nuestra nación y no de los puertorriqueños en su diversidad, complejidad y concreción.

La narrativa de Sánchez y de Córdova se asemejan por el uso de la ironía y la parodia, de un lenguaje que expresa la violencia en sus contenidos, del realismo como forma de afrontar la realidad y por la recuperación de formas belavalinas. Sin embargo, se distancian precisamente por la finalidad que otorgan al uso de la ironía. Por otro lado, el realismo grotesco de Córdova se matiza y se impregna de poesía. No debemos olvidar que estamos ante la narrativa de un poeta (Para llenar de días el día (1985); Militancia contra la soledad (1987).

Después de esta introducción queremos examinar dos textos que abordan el tema de los veteranos de guerra para explicar cómo se articula en ellos la ironía.

\section{LA IRONIA COMO ESTRATEGIA DISCURSIVA}

En la literatura modernay, en especial, en algunos autores puertorriqueños -como Sánchez y Córdova-, encontramos el uso de la ironía como una de las formas de construcción de los textos. La utilización de este recurso responde por una parte al carácter humorístico de sus textos $\mathrm{y}$, por otra, al hecho de que la ironía le permite penetrar en el centro mismo de la sociedad que el escritor examina. Es decir, el uso frecuente de la ironía se explica porque para su producción se requiere una sociedad compleja atravesada por una red de discursos de poder, ideológicos y culturales que en la ironía son confrontados en toda su falsedad. Estos discursos y hechos constituyen el sentido literal sobre los que se elabora el nivel primario de la ironía. No es extraño, pues, que en una sociedad en crisis económica y social como la puertorriqueña, algunos escritores prefieran utilizar este recurso como estrategia discursiva de sus narraciones para desarticular y descomponer los engañosos discursos del poder.

En la ironía, por tanto, hay un primer nivel, el de lo literal, que es lo que se dice; $y$ un segundo nivel, oculto, en el que se encuentra lo que se pretende decir. En toda ironía hay, pues, reticencia; información que se calla pero que está insinuada. El silencio se constituye, entonces, en una de las marcas para la descodificación de la ironía. Por otro lado, la ironía necesita el contexto para que se entienda su significado; ya que es sobre él que se construye el nivel primario o sentido literal. La existencia de la ironía no se determina únicamente por la diferencia entre el nivel primario y secundario, sino por la oposición entre el sentido literal y el contexto. Debemos entender como contexto tanto el referente (recordemos que el humor es siempre realista) y el universo narrativo que articula dichoreferente. En la ironía esta imbricación de componentes textuales y extratextuales, que aparecen como marcas en el discurso, es la que permite reconocer la existencia del segundo nivel.

La presencia del componente extratextual (contexto ideológico, cultural, hechos reales) indica que el uso de la ironía exige conocimiento del referente en 
el que se produce el texto de contenido irónico, lo que plantea el problema de la contemporaneidad del humorismo. La ironía exige un lector cómplice, un colaborador inteligente situado en el presente que pueda, mediante el conocimiento de los componentes textuales y extratextuales, descodificar el verdadero significado de las palabras. Esto no quiere decir, sin embargo, que los lectores futuros no puedan descodificar la ironía, sino que para dar con el significado real tendrán que realizar una investigación arqueológica para reestablecer las complicidades (véase por ejemplo, el trabajo de Córdova en este volumen sobre el significado de la palabra turismo en los cuentos de Belaval). La prueba de la necesidad de un lector situado en el presente lo es la ironía oral. En ella la relación entre el emisor y el receptor es un hecho tangible, por lo que la descodificación del nivel primario al secundario es más fácil puesto que está auxiliada por gestos y entonación. Estos componentes ausentes de la ironía escrita se sustituyen por una complicidad basada entre el contexto y el lector que reconoce en el discurso las marcas que lo llevan a resolver el enigma de lo ocultado en el sentido literal. Si el lector no es audaz, es decir, si no establece la complicidad o no reconoce las marcas que nos conducen al nivel secundario, prevalecerá el primer nivel. En este caso triunfa la construcción ideológica, el discurso de poder que se afirma como verdadero.

El triunfo del sentido literal en el lector ingenuo responde a la aceptación por parte de éste del principio de verdad que debe presidir todo acto de habla. Pero la ironía viola este principio porque el primer nivel es una ficción, una máscara, una exterioridad visible cuyoanálisis profundo muestra su interioridad real. Esto no quiere decir que la ironía sea una negación; más bien se trata de una inversión, de un desplazamiento e incluso de un rechazo del nivel primario que es perfectamente creíble y aceptable, y que prevalecería si en su propio conjunto no existiera el segundo nivel. La ironía es, por lo tanto, una síntesis en la que, paradójicamente, se da un proceso de separación, de distancia crítica para establecer un contraste entre los dos niveles e invertirlos.

En resumen, la ironía es un recurso apreciado y utilizado por los escritores puertorriqueños Luis Rafael Sánchez y Félix Córdova Iturregui porque su esencia y estructura se origina en el corazón mismo de la sociedad que comparten. Constituye una estrategia crítica fundamental para examinar, desmontar, desarticular y burlarse en sus narraciones de la situación colonial que rige la vida de los puertorriqueños. Veamos algunos ejemplos de articulación de la ironía en estos dos autores.

"La recién nacida sangre".

El humorista sabe que ... la materialidad de la vida $\tan$ varia y compleja contradice luego ásperamente aquellas simpli-ficaciones ideales, obliga a actos, inspira pensamientos y sentimientos opuestos a toda aquella logica 
armoniosa de los hechos y de los caracteres concebidos por los escritores ordinarios.

Luigi Pirandello (1920)

"La recién nacida sangre" es el único de los cuentos del libro En cuerpo de camisa (1966) ${ }^{2}$ que trata el tema de la guerra de Corea. El narrador menciona el conflicto bélico de manera incidental totalmente desprovisto de importancia: "éste era el cuento de Pepé Dolores, los alicaídos, el overol acribillado, experiencia en la vaina de Corea" (57). El uso del sustantivo vaina (contrariedad, molestia) para degradar o disminuir el significado de la guerra es indudablemente un procedimiento humorístico y nos expresa de inmediato el caracter irónico del texto. Porque si bien vaina en el sentido literal aparece como molestia, en su sentido inverso encontramos que se trata de maltratar afrentosamente de obra y de palabra. Maltrato que aparece reiterado y marcado en el contexto por el adjetivo acribillado y el topónimo Corea. El contexto nos indica que no se trata de una simple molestia o contratiempo sino de un hombre herido, agujereado en el campo de batalla. Corea, al igual que Vietnam, significó para el país un número altísimo de bajas, mutilados y de afectados por el "postwar syndrome" en comparación con las estadísticas de los soldados blancos de la nación norteamericana. "En Corea, por ejemplo, los norteamericanos sufrieron una baja por cada 1,125 personas, mientras que los puertorriqueños sufrieron una baja por cada 660 . En Vietnam murieron un total de 1,300 puertorriqueños y el $56 \%$ de los veteranos de esa guerra sufren desórdenes mentales" (Rodríguez Beruff, 1988, 154). Datos exactos que revelan el "maltrato", la opresión de la que es objeto la población masculina puertorriqueña al ser enviada a participar en las guerras de la metrópoli colonial.

La mención de la realidad de la guerra, desvalorizada en el cuento, se eleva a un primer plano mediante el procedimiento de la ironía. Una vez invertido el nivel secundario, podremos entender el significado cabal del cuento y toda su ironía.

El ocultamiento del dato - reticencia - ocurre desde el título mismo. "La recién nacida sangre" alude a los "nacimientos" de los hijos de Pepé Dolores sin que laguerra aparezca como una marca fundamental. El título ocultaigualmente otra verdad profunda: no se trata de recién nacidos sino de natimuertos. Otra vez laironía opera como fuerza estructurante. El lector percibe una contradicción entre el título y el motivo de la muerte que aparece enunciado al inicio del texto, "estaba cansado de treparse el muerto al hombro"; "los muertos largan una sombra que sigue a uno siempre". Pero, ¿quiénes son estos muertos? A través de la lectura nos enteramos de que son los hijos de Pepé Dolores en un primer nivel. Sin embargo, hay una ambigüedad con respecto a los muertos que ha quedado establecida por el carácter irónico del texto. Pepé Dolores es un hombre

${ }^{2}$ Para las citas utilizaremos la edición de 1971. 
marcado por la muerte. Llega a su matrimonio con ese estigma. Sus ojos "alicaídos", su tristeza, su falta de fuerzas, son producto de la "experiencia en la vaina de Corea". Pepé Dolores carga en sus hombros los muertos de la guerra, muertos que arrojan sobre el una sombra larga "que sigue a uno siempre?". El problema radica en que el personaje asume, en parte, la culpa de los natimuertos como un rasgo inherente a su persona: "semilla mía dañada" o, de otro lado, como responsabilidad de su mujer: "el vientre de ella era una tumba".

La guerra produce esta distorsión. El personaje, enajenado como consecuencia de su participación en un conflicto bélico que nada tiene que ver con él, se acerca a la realidad de manera fragmentaria. Ello le impide ver la totalidad y complejidad de la existencia. Su interpretación de la realidad es tan pasmosamente literal que resulta trivial y hasta frívola, incluso, por momentos, nos parece cínica. Pepé Dolores, incapaz de reconocer a sus verdaderos agresores, agrede y asesina a su mujer, contra quien descarga horizontalmente toda su rabia y hostilidad. El patetismo del personaje nos lleva a situar la narración en la corriente del humor negro grotesco (véase a Winston, 1972).

En el humor negro grotesco prevalece la fragmentación del cuerpo cuyas partes se exageran ("el vientre de ella era una tumba", "la falda crecía", "el vientre se alzón). El vientre se transforma en una amenaza viva. Sin embargo, la muerte domina pero "ocurre en una forma ridícula y nunca dignificada" (Winston, 1972, 283). Cuando Marcela anuncia su cuarto embarazo, la noticia es recibida por el personaje en forma desmesurada y por los lectores por la marca gráfica de las mayúsculas: "Hasta la noche que su voz me subió por la oreja. Letra que me sacó de la garganta, letra que me quitó la mirada, hasta sumar: ESTOY ENCINTA". Tan pronto como la mujer concluye su anuncio se desata la violencia: "cuatro cruces escribieron de su muerte, cuatro cruces que mi cuchillo obligara. Tesa, tesa, tesa, como nuevo Pepe Lolón. El resultado es el encarcelamiento del protagonista.

El lector, que ha descodificadola ironía, descubre los significados profundos. Pepé Dolores ejecuta un doble acto de destrucción: la del ser amado y la de sí mismo. No puede entender la totalidad en la que se inserta el sentido de la autodestrucción: la muerte que lo persigue es producto de la violencia de la situación colonial. Su participación en la guerra, aún su propia destrucción, responde a dicha violencia. El mundo colonial, que todo lo distorsiona, construye enunciados de poder. Un mundo ideal en el que la violencia y la opresión son silenciados y el racismo impone un sentido de inferioridad y de culpa (véase a Fanon 1969). Por ello Pepé Dolores es incapaz de dirigir su violencia contra sus opresores y la dirige en primera instancia contra su mujer (ejemplo típico de una situación de violencia doméstica) y en segunda instancia de violencia contra sí mismo.

La guerra de Corea adquiere ahora su verdadero lugar en la narración. El patetismo del personaje, su tragedia, nos remite a ese hecho fundamental.

Para concluir, habría que señalar que la ironía convierte este cuento en un epígono paródico de los cuentos de guerra de la generación anterior para cerrar 
con el tema de Corea. El cierre humorístico era necesario, puesto que ya en 1966 había en el horizonte de los puertorriqueños una nueva guerra. El humor establece una distancia crítica, distorsiona y destruye las formas estrictamente realistas de acercarse al tema, el tono serio y pesimista de las narraciones. En este sentido, "La recién nacida sangre" invierte, parodiando, los modos de producción de la generación anterior y se distancia de ellos mediante una nueva propuesta: la de una literatura humorística.

"El momento divino de Caruso Llompart".

En toda ideología los hombres y sus relaciones se nos muestran de cabeza ... el fenómeno responde al mismo proceso histórico de la vida, de la misma manera que la inversión de los objetos en la retina responde a su proceso de vida físico. Marx

Pensamos en un pueblo que hace historia, que transforma al mundo y se transforma a si mismo. B. Brecht

Caruso Llompart pertenece al mundo de la orilla, que en Puerto Rico quiere decir del arrabal. Tal vez porque el paradigma de los arrabales lo constituyen La Perla y el Caño Martín Peña, que se desarrollaron a la orilla del mar y del mangle respectivamente. Gente de orilla es, por tanto, expresión de marginalidad. Así, la mayoría de los personajes de este volumen son marginados sociales. Según Cabrer (1987) "la marginación social es el tema que hilvana las historias".

Caruso Llompart es un veterano de la guerra de Vietnam. Esperaríamos que, si fue a la guerra a defender la democracia, al regresar al pais tuviera un lugar de prestigio en la sociedad. En el nivel literal de las formulaciones ideológicas, éste sería la propuesta del discurso de poder. Pero, como precisamente el poder construye ropajes y máscaras engañosas, el texto de Córdova se dirige a cuestionar la esencia misma del poder en sus diversas manifestaciones. En este sentido, los temas que subyacen en los cuentos "apuntan en un primer plano directamente hacia el carácter represivo del estado y en un segundo plano hacia la fuerza implacable del imperialismo" (Cabrer, 1987), 24. La estrategia para descubrir dicha realidad es la ironía.

Mediante la ironía, Córdova define a sus personajes con respecto de sus contrarios y de esta oposición se produce la inversión irónica. El personaje de Caruso Llompart es confrontado con los militares, con los miembros de las iglesias, con sus compatriotas y, aún, con su propia madre. El soldadoLlompart, reclutado por el ejército norteamericano para ir a defender la democracia en Vietnam, es licenciado y enviado de vuelta rápidamente a su casa porque constituye un peligro para la seguridad nacional. Pero, ¿cuál es el problema de Caruso? Padece de una enfermedad, de un "peligroso prejuicio", de "un virus espiritual" que podría transmitirse al resto del batallón. Esa enfermedad, 
dictaminada por "un venerable cura [que] no pudo guardar el secreto" de la confesión es denominada democratismo síquico acentuado. Los síntomas de la misma se expresan inmediatamente y preocupa a los democráticos defensores de la democracia:

los oficiales de su batallón pu dieron apreciar que no distinguía a los vietnamitas. No habia en su mente el más mínimo indicio de lo que era un vietcong. Cuando uno de los psiquiatras del ejército le hizo unos exámenes en que tenía que dibujar a los soldados enemigos, el pobre Caruso dibujaba hermosos soldaditos estadounidenses, todos rubios y con un pedacito de mar en los ojos. Aquel fanático soldado, que nunca disparo un tiro contra nadie, a pesar de las ordenes feroces que recibía, no distinguía a los negros ni a los puertorriqueños (87-88).

Poco a poco vamos comprendiendo que el personaje sufre una doble marginación; no sólo por su extracción social "infeliz puertorriqueño del barrio Guaraguao de Bayamon" (de orilla) sino por sus ideas. Los epítetos que se utilizan lo condenan a la soledad de un paria fanático soldado, extravagante pacifista, o de una especie de lepra peligrosa enfermedad, lamentable prejuicio, virus espiritual, peligroso prejuicio, locura progresiva. Convertido en un enajenado, en un loco, Caruso aterriza en la casa de su madre. La ironía nos obliga a examinar y contraponer los conceptos de democracia, libertad e igualdad de los militares y, del cura y los de Caruso Llompart. La democracia de los primeros se convierte en una anti-democracia y los lectores, al hacer el proceso de inversión, descubrimos los mecanismos ideológicos y de poder producidos para defender los intereses de clase y no los procesos democráticos. De lo contrario, verdadero demócrata, no hubiera sido convertido en un saboteador, en un subversivo. El imperialismo nos muestra su cara. La ironía desarticula su máscara engañosa y exterior.

La guerra de Vietnam opera como un trasfondo, como un hecho pasado en la vida del personaje que determina su situación presente. Tanto Caruso como su madre viven de la pensión del ejército; pensión que depende de la locura del personaje. La madre de Caruso desea que su hijo se cure pero que mantenga las apariencias "para no perder los beneficios de la pensión". Por otro lado, la vida en el ejército le permite a Caruso adquirir conciencia de la hipocresía, falsedad y estafa de los predicadores religiosos. El sabe, por ejemplo, que Yiye Avila podría ocupar un lugar en la sociedad porque su situación económica estaba resuelta, y la pensión del ejército significaba en él un compromiso ideológico:

cuando llegaron a la iglesia y el hermano Yiye comenzó su prédica, bajando nubes y subiendo relámpagos, agrietando el universo para que se viera por un instante la caldera de Satanás, Caruso se sintí avergonzado de solo pensar que también aquel ruidoso fanfarrón podía estar alli porque había sido pensionado por el ejército (89).

La confrontación entre Caruso y Yiye Ávila ocurre cuando la madre decide llevarlo para que le hagan la "sanación" porque su hijo tenía "todos los goznes 
del cerebro fuera de lugar". La madre había sospechado que Caruso se estaba haciendo el loco para salirse del ejército y no quería que ello se descubriera por temor a perder la pensión. Pero cuando Caruso tiene su "momento divino"; cuando "poseído por la imagen de un Jesús rabioso e implacable" “fue al pastizal que estaba a uno de los lados de la iglesia, arrancó unos bejucos y regresó intrépido, látigo en mano, a arrojar a los mercaderes del templo", no le queda duda a la madre de que está loco.

Nuevamente, Caruso es sometido a una doble marginación. Los feligreses llaman a la policía porque "nadie recordó al Dios de los relámpagos y de los terribles castigos" y pensaron que Caruso era "el mismo Plutón que había salido de las cavernas", "el endemoniado". El arresto de Caruso produce la tranquilidad de sus compatriotas, e incluso de su madre:"entre los feligreses, la atribulada doña Benedicta encontraba un solo motivo que la satisfacía: su hijo jamás perdería aquella jugosita pensión" (92). La actitud de la madre no debe extrañarnos pues ella también ha asimilado los discursos de poder. Ella viene de un "trasfondo de depurado republicanismo". La traición a su propio hijo se debe no sólo al interés económico sino a la aceptación de la ideología dominante frente a la cual su hijo resulta, sin quererlo, un subversivo "debo llevarte a la iglesia para que hables con Yiye Ávila. A ver si se te quitan todas esas majaderías sobre la igualdad" (89).

Marginado por el poder y por la sociedad de manera violenta, Caruso se refugia en la soledad de la conciencia "no es ésta la soledad de estar sin compañía, es la profundísima soledad de aquél a quien lo obligan a sobrevivir marginado" (Cabrer 1987, 23). Cuando comienza el cuento encontramos a Caruso buscando a Jesús en el huerto de Getsemani. Quiere descargar culpabilidad de haber "usurpado el lugar histórico de Jesús", pero también quiere decirle algo más. Algo que, en el cuento, se oculta persistentemente mediante la reticencia "pensó encontrarse con Jesucristo y decírselo". ¿Qué es eso que quiere decirle? En realidad no sabemos, porque Caruso no encuentra a Jesús sino a su madre regando las flores y, además, se da cuenta de que está en calzoncillos. La búsqueda de Cristo se aplaza, puesto que la vestimenta no era la adecuada para ver al salvador. Sospechamos que el "quejumbroso mensaje" que habría de llevarle tiene que ver con la traición.

Debemos recordar que Cristo va a Getsemaní a orar antes de ser entregado por Judas que no se encontraba en el huerto. La traición es el desenlace de este episodio. El modelo literario nos impone la descodificación. El olvido de los pantalones lleva a Caruso a una reflexión sobre la realidad que vincula con el poder de las iglesias. En este sentido, el mensaje de Caruso se refiere a la traición de los predicadores que se han convertido en mercaderes: "lo que ahora sorprendía a Caruso Llompart era la conciencia que había cobrado sobre la explosiva utilidad de un olvido para comprender la realidad. Fue necesario lanzarse a buscar a Jesucristo en el huerto de Getsemani, sin pantalones, para darse cuenta del verdadero sentido que tenía la existencia de todos aquellos bellacos de la religión que vestían y vivían con un gran lujo para esconder las 
penurias del espiritu ... los hombres que ahora le preocupaban no se parecian a Jesús y todos usaban su nombre y su prestigio para seguir crucificándolo" (87).

A los discursos de poder militarista y religioso se opone el discurso de Caruso y su acción ofensiva. El cuento pone la realidad de cabeza. En este proceso hemos penetrado en la interioridad del nivel literal para comprender la verdad de su opuesto, el discurso de la gente de orilla. El lector comprende ahora las causas de la marginación y la locura de Caruso. Aún más, asume una postura cómplice con el personaje reconociendo su verdad.

Como hemos podido ver en el cuento analizado, la ironía tiene una forma distinta a la tradicional. Existen los dos niveles: el literal (lo que se dice) y el nivel secundario (lo que se quiere decir) que es el sentido inverso del primero. Sin embargo, en el cuento de Córdova ambos niveles aparecen explícitamente en contradicción permanente. Se trata de los discursos de poder, de sus actos frente al discurso y a los actos de Caruso Llompart. En la interpretación de los dos niveles, el lector debe privilegiar el discurso de la razón y provocar la inversión, inversión que ya está propuesta desde el texto mismo al explicitarse. El texto nos ofrece soluciones y nos indica de qué lado debemos estar. En este sentido su visión del realismo coincide con la de Bertold Brecht: "ser realista es escribir poniéndose en el lugar de la clase que brinda las soluciones más amplias a las dificultades más agudas de la humanidad" $(1976,64)$.

Este caso de la ironía como una estructura dialéctica, de cuya confrontación surge no sólo la inversión irónica sino la síntesis interpretativa, expresa la necesidad de examinar la realidad en toda su complejidad para transformarla. Así, el uso del recurso tiene unas profundas connotaciones políticas y una posición frente a la literatura que Cabrer $(1987,23)$ ha resumido muy bien:

es imperioso mencionar que Félix Córdova Iturregui no acepta el precepto de que la literatura no puede, o por lo menos no debe, ofrecer soluciones a los problemas sociales: sabe que con pintar la realidad no basta; afirma que la literatura puede ofrecer un espacio a la explicación y la explicación es la semilla de posibles soluciones.

\section{CONCLUSIONES}

En el presente trabajo hemos examinado dos cuentos de escritores que, aunque separados por el tiempo, tienen algunos rasgos en común. Tanto Sánchez como Córdova son escritores de transición con una mirada crítica, por momentos paródica, hacia la producción literaria puertorriqueña. Ambos se ubican dentro de la corriente del realismo, pero de un realismo marcado por el humor. Entre sus modelos se destacan Brecht y el puertorriqueño Emilio S. Belaval.

El humor de Sánchez es más cercano a lo que Bakhtin ha llamado cultura popular de la risa. El lenguaje narrativo se impregna de rasgos carnavalescos y humoristicos, como la parodia, la degradación, las obscenidades, la burla, el 
ridículo, el absurdo, la ironía. Estos rasgos penetran el discurso del narrador y se borra la distancia con respecto al discurso de los personajes. A veces el humor, marcadamente grotesco, invade la zona del humor negro. Los personajes, distorsionados, ridiculizados, a veces son abandonados a su propio destino para que el lector los rescate y llegue a sus propias conclusiones. El humor de Sánchez expresa las contradicciones de una realidad desarticulada y grotesca. Las conclusiones pertenecen a la esfera del lector.

En el caso de Córdova, el humor es menos grotesco, casi no hay rasgos de carácter carnavalesco. Se trata de un humor que se acerca más al Lazarillo o, más bien, al de Cervantes. Como este último, su mirada es comprensiva y muchas veces, compasiva. El narrador en tercera persona que examina la complejidad del universo narrativo captando, como en una síntesis, la totalidad de las contradicciones, nos va mostrando las causas y los efectos de las cosas, construyendo para el lector una realidad que se nos abre como conocimiento. El humor tiene la intención de hacernos entender y comprender la realidad desde la distancia crítica producida por la risa.

La diferencia entre el uso del humor en Sánchez y en Córdova puede reconocerse en la forma en que ambos articulan la ironía. Hemos seleccionado para ello dos cuentos que tratan el tema de la guerra como un conflicto casi invisible, pero avasallante, que domina la vida de los personajes. Al examinar este referente histórico en "La recién nacida sangre" de Luis Rafael Sánchez y "El momento divino de Caruso Llompart" de Félix Córdova Iturregui, encontramos que su paso a la ficción se articula por medio de la ironía. Pero la forma que adquiere en uno y en otro es diferente. En cada caso, la forma de la ironía expresa un manejo distinto del recurso literario, una posición frente a la literatura puertorriqueña, frente a la realidad y al destino de la nación puertorriqueña. En último término el uso que se le da a la ironía nos explica la función del arte en una sociedad matizada por la violencia. Y nos recuerda una vez más que el arte ocupa un lugar en la sociedad y, como tal, es producto de ella. El significado estético debemos entenderlo dentro de la totalidad de la realidad en que se produce. A través de la mirada humorística e irónica de Luis Rafael Sánchez y de Félix Córdova Iturregui volvemos a un tema inquietante en la tradición literaria puertorriqueña, tema que penetra en nuestra realidad política y reitera los desastres de la guerra.

\section{BIBLIOGRAFÍA}

Córdova Iturregui, Félix. El rabo de lagartija de aquel famoso señor rector y otros cuentos de orilla. Río Piedras: Ediciones Huracán, 198. 85-92.

Cabrer, Sebastián. "Félix Córdova Iturregui: El rabo de lagartija de aquel famoso señor rector y otros c uentos de orilla”. Pensamiento Crítico 58. marzo-abril, 1987. 23-25. 
Colón, Eliseo. "Félix Córdova Iturregui: El rabo de lagartija de aquel famoso señor rector y otros cuentos de orilla." Revista Iberoamericana 144-145 . Julio-diciembre, 1988. 1045-1047.

Sánchez, Luis Rafael. En cuerpo de camisa. Río Piedras: Editorial Cultural,1971. 57-60.

Sánchez, Luis Rafael. Fabulación e ideología en la cuentística de Emilio S. Belaval . San Juan: Instituto de Cultura Puertorriqueña, 1979.

Sánchez, Luis Rafael, y Arcadio Díaz Quiñones. "El oficio y la memoria". (inédito), 6 sesiones. 1979.

Sánchez, Luis Rafael. "El oficioy la memoria". Sin Nombre 1. abril-junio, 1981. 27.

Vázquez Arce, Carmen. Salsa y control: el discurso expositivo de Luis Rafael Sánchez. México, D.F.: UNAM, 1984. (Tesis doctoral inédita).

Bakhtin, Mikhail. La cultura popular en la Edad Media y el Renacimiento. Barcelona: Barral Editores, 1974.

Brecht, Bertold. Escritos sobre teatro 2 . Buenos Aires: Nueva Visión,1976.

Estades, María Eugenia. La presencia militar de Estados Unidos en Puerto Rico 1898-1918. Río Piedras: Ediciones Huracán, 1988.

Fanon, Frantz. Los condenados de la tierra. México: D.F. Fondo de Cultura Económica, 1969.

García, Neftalí. "Puerto Rico siglo XX: Lo histórico y lo natural en la ideología colonialista”. Pensamiento Crítico 1, 8. Documentos. septiembre,1978.

González, José Luis. El país de cuatro pisos y otros ensayos . Río Piedras: Ediciones Huracán, 1980. 91-104.

Halliday, M. A. K. Language a Social Semiotic . Baltimore: University Park Press, 1978.

Hodge \& Kress. Social Semiotics . Ithaca: Cornell University Press, 1988.

Hutcheon, Linda. "Ironie et parodie: stratégie et Structure". Poétique 36 1988. 467-477.

Lotman, Jurij. Semiótica de la cultura . Madrid: Cátedra, 1979.

Marqués, René. En una ciudad llamada San Juan. Río Piedras: Editorial Cultural, 1970.

Muecke, D.C. "Analyses de l'ironie". Poétique 36 . 1978. 478-494.

Pirandello, L. "El humorismo". Obras escogidas . Madrid: Aguilar, 1963. 917. 1101.

Rodríguez Beruff, Jorge. Política military dominación. Río Piedras: Ediciones Huracán, 1988.

Winston, Mathew. "Humour noir and Black Humor". H. Levin ed., Veins of humor. Cambridge: Harvard University Press, 1972. 269-284. 
